
www.globaljournalseries.com, Email: info@globaljournalseries.com

\title{
KNOWLEDGE, ATTITUDE AND PRACTICE OF POST-EXPOSURE PROPHYLAXIS (PEP) TO HIV AMONG DOCTORS IN A NIGERIAN TERTIARY HEALTH INSTITUTION
}

R. E. AGBulu, O. UdOFIA, M. EKOTT, E. PETERS, K. K. IMANANAGHA, A. OYO-ITA, P. O. AGBULU AND I. E. CHUKU

(Received 22 January 2010; Revision Accepted 4 April 2013)

\begin{abstract}
Introduction: The HIV/AIDS pandemic still ranks one of the foremost causes of death in developing world. The present prevalence of HIV/AIDS is $5.0 \%$ for Sub-Saharan Africa and the Nigerian figure is $3.01 \%$. The rate of infection of a previously non-infected individual in this sub-region is set at 160,000 individuals daily. With such a high prevalence, it of importance that caregivers and particularly medical doctors arm themselves with sufficient knowledge of postexposure prophylaxis.

Design: Cross sectional descriptive study.

Participants: The study took place among 81 doctors in a tertiary health institute in Nigeria, the University of Calabar Teaching Hospital.

Methodology: A semi-structured questionnaire was administered to the subjects using a random sampling method. These questionnaires highlighted their departments, ages and ranks. Their levels of knowledge and indications for PEP as well as their attitudes to this procedure using a modification of the Likert Attitude Scale were also assessed. There were 15 attitude parameters and each attracted a maximum score of 5 points with a total of 75 points. Respondents were scored and the attitude scores were graded thus; negative attitude - <35 points; bare positive -36 - 50 points; positive $-51-65$ points; super-positive - $>65$ points. The subjects were also given an opportunity to suggest ways of improving on the practice of PEP in their various practices.

Results: This showed that the knowledge of PEP was satisfactory, however only about half of the respondents mentioned specific indications for PEP. The doctors' source of information about PEP was also too medically oriented and not broadminded enough for his position as the decision maker / head of the medical team. Respondents attitude towards PEP was positive and very important suggestions were made for better implementation of PEP.

Conclusion: The knowledge of PEP is satisfactory in UCTH, Calabar and issues that need to be addressed in our practice border on of information dissemination and measures aimed at increasing the awareness of PEP in our society.
\end{abstract}

KEYWORDS: Knowledge, Attitude, Post-Exposure Prophylaxis Knowledge, Attitude and Practice of post-exposure prophylaxis to HIV

\section{INTRODUCTION}

The HIV/AIDS pandemic still ranks one of the foremost causes of death in the developing world. The present prevalence of HIV/AIDS is $5.0 \%$ for SubSaharan Africa (HIVinSite, 2003) and the Nigerian figure is $3.01 \%$ (UNAIDS/WHO Working Group on Global HIV/AIDS and STI Surveillance, 2008). The daily rate of infection of a previously non-infected individual in this sub-region is set at 160,000 individuals (McNicholl et al, 2000).

The broad implications of the daily rate of infection is two pronged; firstly, there will be an increasing need to offer a wide range of services by the
Health Care Worker (HCW) to the People Living with HIV/AIDS (PLWHA). This would lead to an increased risk of occupational exposure (O'Brien, 1998; Morbidity and Mortality Weekly Report, 2008 and Denise et al, 1999) particularly when there is a breach of infection prevention protocol. The consequences of having an infected health care worker are of grave public health importance. The economic impact of losing work hours and also the possibility of infecting a previously uninfected patient and even re-infection of an already infected patient cannot be overlooked. These attendant risks lead to stigmatization of the PLHWA and may ultimately result in the delivery of sub - optimal care and support for these patients. (Steward et al, 2008)

R. E. Agbulu, Department of Internal Medicine, University of Calabar Teaching Hospital, Calabar, Nigeria

O. Udofia, Department of Internal Medicine, University of Calabar Teaching Hospital, Calabar, Nigeria

M. Ekott, Department of Obstetrics \& Gynaecology, University of Calabar Teaching Hospital, Calabar, Nigeria

E. Peters, Department of Internal Medicine, University of Calabar Teaching Hospital, Calabar, Nigeria

K. K. Imananagha, Department of Internal Medicine, Niger Delta University, Yenogoa, Nigeria

A. Oyo-Ita, Department of Community Medicine, Niger Delta University, Yenogoa, Nigeria

P. O. Agbulu, Department of Pharmacy, University of Calabar Teaching Hospital, Calabar, Nigeria

I. E. Chuku, Department of Pharmacy, University of Calabar Teaching Hospital, Calabar, Nigeria 
It is only mandatory that beyond the sophisticated drugs being developed, the caregivers and particularly medical doctors arm themselves with sufficient knowledge of this very important modality of prevention in the case of an accidental exposure for themselves and for the public in the interest of all concerned. (O'Brien, 1998)

The practice of Post - Exposure Prophylaxis (PEP) has been proposed for a lot of medical conditions like Tetanus (Morbidity and Mortality Weekly Report, 2008), Hepatitis B etc (Cosens et al, 2009) but it is with the advent of HIV/AIDS that this term has almost become a "household word" medically. This is not very surprising when one puts into consideration the alarming rate of spread of this pandemic and the even poorer prognosis particularly for sufferers in the developing world. It will be pertinent also to remind ourselves that nowhere in the practice of medicine has the scope of PEP become so broadened to incorporate not only medical staff after exposure to infected serum, but to babies in utero and immediately after delivery, rape victims and even after unprotected sexual relationships in serodiscordant couples. (Mortality Weekly Report) Other possible routes of infection are through organ transplantation, (Grady, 2008 \& INFONIAC.com. 2008) artificial insemination (Ross et al, 199; CDC / MMRW, 1990 and Araneta et al, 1995) and use of unsterilized needles among intravenous drug use. (Smith et al, 2005)

This study aims to assess the level of knowledge that doctors in the University of Calabar Teaching Hospital have about this very topical issue, their attitudes and as well as modalities to improve their mode of practice of this life saving procedure in our centre.

\section{SUBJECT AND METHOD}

Calabar, the capital of Cross River State could also be referred to as the "Pearl of Nigeria"; what with it's beautiful, scenic atmosphere, very hospitable people and cuisine. Sadly though, this state had the highest prevalence of HIV/AIDS in the country about 8 years ago $(\mathrm{FMH}, 2003)$ but this rate has halved at the last study conducted by the Nigerian government (UNAIDS/WHO Working Group on Global HIV/AIDS and STI Surveillance). Calabar has ten primary healthcare facilities, a general hospital and two specialist hospitals - the Infectious Diseases Hospital (IDH), and the NeuroPsychiatric Hospital. There is also one tertiary health facility - University of Calabar Teaching Hospital (UCTH) and 51 privately owned facilities. The Teaching hospital, General Hospital and Infectious Diseases Hospital also serve as sites for the Presidential Emergency Plan for AIDS Relief (PEPFAR). The Teaching Hospital which is a 600-bed (UCTH HOSPITAL INFORMATION CENTRE) hospital serves as the main referral center for the State and provides a wide range of clinical services for patients.

Semi-structured questionnaires were administered to 81 doctors who were seen at the Outpatient Clinics of all departments of the University of Calabar Teaching Hospital.

Questionnaires highlighted their sociodemographic data (age), as well their ranks and departments. An attitude scale based on the Likert Attitude Scale was administered to them. The attitude scale had 15 parameters assessed; 6 out of these were positive while 9 were negative. The respondents were scored $5-1$ for the most agreeable response to the most unagreeable response respectively for a positive attitude parameter and the reverse was done for the negative attitude parameters.

\section{STATISTICAL ANALYSIS}

Data was analyzed with the aid of EPI info 2002 version 6 software and presented in the form of percentages, tables and graphs. Chi-square test of significance was applied and the level of statistical significance was fixed at $p$ value $=<0.05$.

\section{RESULTS}

The results obtained from this study are shown in Tables 1 - 6: Majority of the respondents 37 (45.7\%) were recruited from the intermediate group of doctors in the hospital and $57 \%$ knew what PEP was but $5 \%$ had no clue of what PEP was about. Of the 81 doctors, only $38 \%$ clearly stated the indications for PEP.

Most of the respondents limited usage of PEP to needle prick injuries and $2(2.94 \%)$ mentioned prevention of maternal to child transmission, rape, sexual relationship in serodiscordant couples, organ transplantation and the sharing of unsterilized needles in intravenous drug users.

$45.8 \%$ agreed to the internationally recommended time of $0-2 \mathrm{hrs}$ after exposure; $26 \%$ settled for $0-6$ hrs while $12.5 \%$ and $5.6 \%$ were of the opinion that PEP should be administered 6-12 hrs and beyond $12 \mathrm{hrs}$ respectively. Results also showed the source of information about PEP among respondents and the attitude scores showed an overall positive attitude. 
Table 1: Sociodemographic Data

\begin{tabular}{lcc}
\multicolumn{1}{c}{ AGE } & $\%$ \\
\hline $20-30$ & 24 & 30.00 \\
$31-40$ & 47 & 58.00 \\
$41-50$ & 8 & 10.00 \\
$>50$ & 2 & 2.00 \\
\hline TOTAL & 81 & 100.00 \\
DEPARTMENT & & $\%$ \\
\hline Int. Med & $/ 3$ & 45.68 \\
Spec & & \\
O / G & 14 & 17.28 \\
Peadiatrics & 16 & 19.75 \\
Surg / Spec & 14 & 17.28 \\
\hline TOTAL & 81 & 100.00 \\
\multicolumn{1}{c}{ STATUS } & & $\%$ \\
\hline House officer & 27 & 33.33 \\
J/ Resident & 31 & 38.27 \\
S/ Resident & 15 & 18.51 \\
Consultant & 8 & 9.88 \\
\hline TOTAL & 81 & 100.00
\end{tabular}

Table 2: Comparison of the Knowledge of PEP among the different status of Doctors

\begin{tabular}{lcccccc} 
STATUS & YES & $\%$ & NO & $\%$ & TOTAL & p-value \\
\hline H/O & 23 & 85.19 & 4 & 14.81 & 27 & 0.01 \\
J/RES & 27 & 87.10 & 4 & 12.90 & 31 & 0.25 \\
& 11 & 73.33 & 4 & 26.67 & 15 & 0.47 \\
S/RES & 6 & 75.00 & 2 & 25.00 & 8 & 0.01 \\
CONSULTANTS & 67 & 82.72 & 14 & 17.28 & 81 & \\
TOTAL & 6 & & & &
\end{tabular}

Table 3: Knowledge of the Indications for PEP

\begin{tabular}{llll} 
INDICATIONS & FREQ & (\%) \\
\hline Occupational & Surgical cuts/wounds & 7 & 35.294 \\
Non-occupational & PMTCT & 24 & 10.294 \\
& Rape & 2 & 2.941 \\
& Organ transplantation & 0 & 0.000 \\
& Serodiscordant couple & 3 & 4.411
\end{tabular}


Artificial insemination

Intravenous drug users

Blood Transfusion

No indications

No indications

Total

Table 4: Knowledge of time of administration of PEP

Time

$0-2$ hrs

$0-6 \mathrm{hrs}$

$6-12 \mathrm{hrs}$

$>12 \mathrm{hrs}$

TOTAL

Table 5: Source of Information

\begin{tabular}{lcc} 
Source & No & $\%$ \\
\hline Hospital / other medically related sources & 66 & 73.33 \\
Mass media & 5 & 5.56 \\
NGOs & 7 & 7.78 \\
Church / other places of worship & 1 & 1.11 \\
Family / friends & 4 & 4.44 \\
Posters / billboards & 7 & 7.78 \\
\hline TOTAL & 90 & 100.0
\end{tabular}

Table 6: Attitude Scores for the Doctors in Study

\begin{tabular}{llc} 
ATTITUDE SCORES & FREQ & $\%$ \\
\hline NEGATIVE & 0 & 0.00 \\
BARE POSITIVE & 8 & 14.04 \\
POSITIVE & 44 & 77.19 \\
VERY POSITIVE & 5 & 8.77 \\
TOTAL & 57 & 100.00 \\
\hline
\end{tabular}
Frequency (\%)

$26 \quad$ (36.1)

$9 \quad(12.5)$

$4 \quad(5.6)$

(100.0)
0.000

0.000

0.000

44.117

100.000

$68 \quad 100.000$




\section{DISCUSSION}

Medical science is a very dynamic body of knowledge and with it's growth comes an even greater demand for more specialized services (both invasive and non-invasive) for patients. This poses a great concern for the health care worker (HCW) who is at an ever increasing risk of exposure to HIV/AIDS. (Stephens et al, 2004)

It is necessary therefore that knowledge of PEP is well assimilated and practiced by members of the health care community (O'Brien, 1998). In our study, the doctors interviewed exhibited a satisfactory level of knowledge of the tenets of PEP comparable to their counterparts in other parts of the world. (Ooi et al, 2004) However, the house officers and consultants had a level of knowledge that was statistically significant compared to the other cadres of doctors. This may be a reflection of the high prevalence of HIV in the area of practice (FMH, 2003) and this makes the house officers more cautious and unwilling to be unduly exposed. The consultant on the other hand is the head of the unit and this level of responsibility demands a commensurate measure of knowledge base.

The issue of indications for PEP falls into two broad categories: occupational and non-occupational exposure. The risk of transmission for the initial borders on the type and severity of exposure (Panlilio et al, 2005) while the subsets of the latter have different per act values of transmission risks. (Smith, 2005) In this study, more than one third of respondents showed knowledge of indications for PEP in the occupational setting while a very small proportion (about one-tenth) mentioned indications for PEP in the non-occupational setting. About a third of the respondents were noncommittal on the issue of proffering suggestions for the possible indications for PEP. Expectedly, the doctors in this study would reflexly remember occupational exposure over the non-occupational avenues. This underscores the need for an exploratory study such as this one which will increase the awareness of doctors for non-occupational indications for PEP.

On the subject of source of information about PEP, it became very worrisome when the majority of respondents attested to only assessing information about PEP in medically related material. In as much as this is to be expected, one wonders if this is not a reflection of the abysmal lack of information for this lifesaving intervention outside of medical spheres. Studies in other parts of the world have assessed Knowledge and information about PEP in the military as well as other subsets of professionals. (Merchant et al, 2008) It would therefore not be out of place if there is an increase in the awareness campaign on PEP. These can be embarked on from the pulpits, social and government gatherings, billboards etc.

The attitude of doctors in this study towards PEP was generally positive and very receptive. This corroborates findings in other parts of the world where despite the question of the cost effectiveness of PEP (Pinkerton et al, 2004) and unfounded fears of increasing promiscuity (Martin et al, 2004), PEP is still strongly advocated for. Understandably, after the long arduous years in the medical school coupled with the bleak prognosis for sufferers in the developing world, the health professional would want some form of protection in case of accidental exposure.

After the decision embark on PEP is reached, the next crucial decision is the timing of the administration of these drugs. This is of paramount importance if any benefits are to be achieved. In this study, the majority of respondents (which made up a third) knew that the internationally recommended time of administration is within one hour of exposure. (Panlilio et al, 2005)

About the issue of the respondents' knowledge of the existence of a hospital policy, it was observed that just a slightly higher than half the proportion of doctors attested to the existence to such a policy, one-third of doctors were not sure and a very small number gave a categorically negative answer. This corroborates findings in a Kenyan study where over two-thirds of doctors interviewed claimed a lack of knowledge of any hospital policy (Dieleman et al, 2007) which stood in sharp contrast to Caucasian studies. (Smith, 2005) PEP has become very topical of recent and for a third of the respondents to be uncertain about the existence of such a policy in their working environment is very unwholesome and calls for an urgent reappraisal of the situation by the hospital management.

The study also explored the possibility of improving on the implementation of PEP and the majority wanted more awareness of the hospital policy and better availability of drugs. Other suggestions were:

i. Development of a hospital policy if such did not exist already.

ii. A post - awareness survey if this study is considered to be a pilot awareness study.

iii. Incorporation of PEP drugs into the emergency kits in the casualty and wards.

iv. Respondents demanded for much needed counseling for recipients as well as utmost confidentiality for recipients.

v. Others felt the working environment should be improved on.

Miscellaneous suggestions included granting the affected staff a leave to recuperate, giving monetary compensations, a no-victimization policy for affected staff, better accountability on the part of the pharmacy as well as making PEP a directly observed therapy in a specially created PEP unit.

In conclusion, PEP is a well recommended preventive modality and all hands must be on deck to see to the proper implementation of the

Tenets of PEP. Indeed the advantages of PEP cannot be overemphasized when one considers the far reaching consequences of the lack of it. Therefore PEP should be more information on the tenets of PEP in billboards by NGOs, in the mass media and in our family units as part of sexuality education for our youths.

Surely, before the advent of this long awaited cure - the panacea maybe - those who accidentally come into contact with this virus (either occupationally or non-occupationally) need to be protected.

\section{REFERENCES}

Araneta, M. R., Mascola, L., Eller, A., O'Neil, L., Ginsberg, M. M., Bursaw, M., Marik, J., Friedman, S., Sims, C. A and Rekart, M. L., 1995. HIV transmission 
through donor artificial insemination. JAMA, (273): 11.

Cardo, D., Final Report 17. October 1996 through 31

March 1999. HIV POSTEXPOSURE PROPHYLAXIS REGISTRY, Registry of Health-Care Workers Receiving Postexposure Prophylaxis After Occupational Exposure to Human Immunodeficiency Virus. Sponsored by: Centers For Disease Control and Prevention, Glaxo Wellcome Inc.

CDC, MMRW., 1990. Epidemiologic Notes and Reports HIV-1 Infection and Artificial Insemination with Processed Semen 39, (15);249, 255-256.

Cosens, B., Suter, R., Updated: 2009. Needle-stick Guideline: eMedicine Emergency Medicine.

Dieleman, M., Biemba, G., Mphuka, S., Sichinga-Sichali, K., Sissolak, D., Kwaak, A and Wilt, G., 2007. 'We are also dying like any other people, we are also people: perceptions of the impact of HIV/AIDS on health workers in two districts in Zambia: Oxford University Press in association with The London School of Hygiene and Tropical Medicine; Health Policy and Planning; $1-10$.

FEDERAL MINISTRY OF HEALTH (FMH) Technical Report on the 2003 National HIV Seroprevalence Sentinel.

GRADY D. Four Transplant Recipients Contract H.I.V NEW YORK TIMES, HEALTH COLUMN. Assessed on the $7^{\text {th }}$ of December, 2008.

HIV InSite: Knowledge Base Chapter., 2003. HIV InSite is a project of the UCSF Center for HIV Information. Copyright 2008, Regents of the University of California.

INFONIAC.com, 2007. Tragic Human Error Leads to Transplantation of HIV-positive Organs. Assessed on the $7^{\text {th }}$ of December, 2008.

Martin, J. N., Roland, M. E., Neilands, T. B., Krone, M. R., Bamberger, J. D., Kohn, R. P., Chesney, M. A., Franses, K., Kahn, J. O., Coates, T. J and Katz, M. H., March 26 2004. Use of postexposure prophylaxis against HIV infection following sexual exposure does not lead to increases in high-risk behavior. AIDS. 18, (5): 787-92.

McNicholl, J. M., Downer, M. V., Aidoo, M., Hodge, T and Udhayakumar, V., 2000. Public Health Assessment of Genetic Susceptibility to Infectious Diseases: Malaria, TB and HIV; Genetics and Public Health in the $21^{\text {st }}$ Century. (21): 15-46.

Merchant, R. C., Nettleton, J. E., Mayer, K. H and Becker, B. M., 2008. HIV post-exposure prophylaxis among police and corrections officers. OXFORD JOURNALS OF OCCUPATIONAL MEDICINE; $58,(7): 502-505$.
Morbidity and Mortality Weekly Report., 2008. Recommendations for Post exposure Interventions to Prevent Infection with Hepatitis B Virus, Hepatitis C Virus, or Human Immunodeficiency Virus, and Tetanus in Persons Wounded During Bombings and Similar Mass-Casualty Events - United States, 2008, Recommendations of the Centers for Disease Control and Prevention (CDC); (Vol. 57 - No. RR-6): 6-7

O'Brien, W., 1998. Post-Exposure Prophylaxis: Stopping HIV Before It Gets Going ICAAC 1998 Annual Conference, Chicago, USA.

Ooi, C., Dayan, L and Yee, L., 2004. Knowledge of post exposure prophylaxis (PEP) for HIV among general practitioners in northern Sydney STI ONLINE SEX TRANSM INFEC: BMJ Publishing Group Ltd. (80): 420

Panlilio, A. L., Cardo, D. M., Grohskopf, L. A., Heneine, W and Ross, C. S., 2005. Morbidity and Mortality Weekly Report. Updated U.S. Public Health Service Guidelines for the Management of Occupational Exposures to HIV and Recommendations for Postexposure Prophylaxis. Department of health and human services Centers for Disease Control and Prevention. (54); RR-9. 2 - 8.

Pinkerton, S. D., Martin, J. N., Roland, M. E., Katz, M. H., Coates, T. J and Kahn, J. O., 2004. Costeffectiveness of HIV postexposure prophylaxis following sexual or injection drug exposure in 96 metropolitan areas in the United States.AIDS.; 18, (15):2065-73.

Ross, R. S., Elgas, M and Roggendorf, M.. 1998. HIV-1 Transmission Through Artificial Insemination. Lancet $\quad$ (351); $\quad 9118 ; 1812$.

Smith, D. K., Grohskopf, L. A., Black, R. J., Auerbach, J. D., Veronese, F., Struble, K. A., Cheever, L., Johnson, M., Paxton, L. A., Onorato, I. M and Greenberg, A. E., January 21, 2005. (Morbidity and Mortality Weekly Report) Antiretroviral Postexposure Prophylaxis After Sexual, Injection-Drug Use, or Other Nonoccupational Exposure to HIV in the United States: Recommendations from the U.S. Department of Health and Human Services. (54) RR-2; $2-7$.

Stephens, J. L., Vogel, R. L., Moore, C. C and Lane, J. E., 2004. Acceptance of HIV Post-Exposure Prophylaxis According to Occupation in the Hospital Setting. THE INTERNET JOURNAL OF INFECTIOUS DISEASES. ISSN. (3); 2: $1528-8366$.

Steward, W. T., Herek, G. M., Ramakrishna, J., Bharat, S., Chandy, S., Wrubel, J and Ekstrand, M. L., 2008. HIV-related stigma: Adapting a theoretical framework for use in India. Social Science \& Medicine. (67); Issue 8: 1225-1235. UCTH HOSPITAL INFORMATION CENTRE 
UNAIDS/WHO Working Group on Global HIV/AIDS and STI Surveillance - Epidemiological Fact Sheet on HIV and AIDS; Core data on epidemiology and response; 18.

UNAIDS/WHO Working Group on Global HIV/AIDS and STI Surveillance., July 2008. Estimated number of people living with HIV by country, 1990 2007: 2008 Report on Global AIDS Epidemic, UNAIDS/WHO. 